\title{
Grain refinement and improved hardness / corrosion balance by pulsed electron beam surface treatment of a FeAl alloy
}

\author{
J. X. Zou, ${ }^{1}$ N. Stein, ${ }^{2}$ C. Boulanger, ${ }^{2}$ S. Z. Hao, ${ }^{3}$ C. Dong, ${ }^{3}$ T. Grosdidier ${ }^{1}$ \\ ${ }^{1}$ Laboratoire d'Etude des Textures et Applications aux Matériaux - LETAM (UMR-CNRS \\ 7078), Université Paul Verlaine METZ, Ile du Saulcy, Metz 57012, France \\ ${ }^{2}$ Group d'Electrochimie des Matériaux, Laboratoire d'Electrochimie des Matériaux-LCSM \\ (Nancy-Université \& Université Paul Verlaine Metz, CNRS 7555), Metz 57078, France \\ ${ }^{3}$ State Key Laboratory of Materials Modification, Dalian University of Technology, Dalian \\ 116024, P. R. China \\ jianxin.zou@univ-metz.fr
}

\begin{abstract}
In the present work, it is demonstrated that significant surface modifications can be generated by a low energy, high current pulsed electron beam (LEHCPEB) treatment under the so called 'Heating mode' without surface melting. Using electron back scattering diffraction (EBSD) and transmission electron microscopy (TEM) observations, it is shown that the extremely fast thermo-mechanical cycles generate grain refinement and the formation of vacancies in the surface layer which account for a significant increase of the surface microhardness of a Fe $40 \mathrm{at} \% \mathrm{Al}$ alloy. Comparatively, the polarisation curves measured in 0.5 $\mathrm{M} \mathrm{H}_{2} \mathrm{SO}_{4}$ solution indicate that the LEHCPEB treatment without melting does not change the corrosion behaviour.
\end{abstract}

Keywords: Low Energy, High Current Pulsed Electron Beam; FeAl; Grain refinement; Corrosion resistance

As is well known, the failure of industrial materials usually starts from their surface, especially when the working environment is corrosive or the applied load is moving. Therefore, it is often necessary and effective to improve the global properties of industrial materials by using surface modification techniques. During the past decades, pulsed energetic beams, such as laser, ion and electron beams, have attracted much attention in the field of materials surface modifications. Among these pulsed beam surface modification techniques, the surface treatment by Low Energy High Current Pulsed Electron Beam (LEHCPEB) has been initially developed at the Tomsk Intense Current Research Institute ${ }^{1-3}$. It is well established that improved surface properties (hardness, corrosion resistance) can be obtained by this treatment when the top surface is melted and rapidly solidified $\left(10^{7} \mathrm{~K} / \mathrm{s}\right)^{3,4}$. This is essentially the result of ultra-fine grains formed from the highly undercooled melt ${ }^{5}$, melt surface purification ${ }^{6}$ as well as strain hardening induced by the thermal stresses and shock waves ${ }^{7}$.

In this work, we demonstrate the effectiveness of the LEHCPEB treatment for materials modification without melting of the top surface. This approach is of the outmost importance to get the full potential of this surface treatment technique ${ }^{8}$. In order to study the typical effects induced by HCPEB treatment under the so called "heating mode", a FeAl intermetallic alloy was selected in the present work. It is one of the potential candidates to replace steels for weight saving applications.

The oxide dispersed strengthened (ODS) B2 Fe (40at\%)Al alloy was hot extruded at $1250^{\circ} \mathrm{C}$ from milled powers (with $1 \% \mathrm{Y}_{2} \mathrm{O}_{3}$ ) in the form of a rounded bar ${ }^{9}$. The specimens for the HCPEB treatment were cut perpendicularly to the extrusion axis into thin disks. Thus, the sample normal direction (ND) is parallel to the extrusion axis. The HCPEB treatments were carried out using a "Nadezhda-2" source ${ }^{1,3}$, with parameters including : accelerating voltage; $27 \mathrm{kV}$, energy density; $3 \mathrm{~J} / \mathrm{cm}^{2}$, number of pulses; 5 and 20 , pulse duration; $1.5 \mu \mathrm{s}$, dwell time between pulses; 10 s. 
Fig. 1a shows a typical TEM micrograph of the initial sample. A coarse grained structure with limited dislocation density can be clearly observed. Besides, many $\mathrm{Y}_{2} \mathrm{O}_{3}$ oxide particles (arrowed) are present. They were added at the milling stage of the powder preparation in order to improve strength and restrain grain size coarsening during processing ${ }^{10,11}$. These oxides are fairly homogeneously distributed inside the grains or at the grain boundaries. Their size ranges from several tens of nms to about $2 \mu \mathrm{m}$.
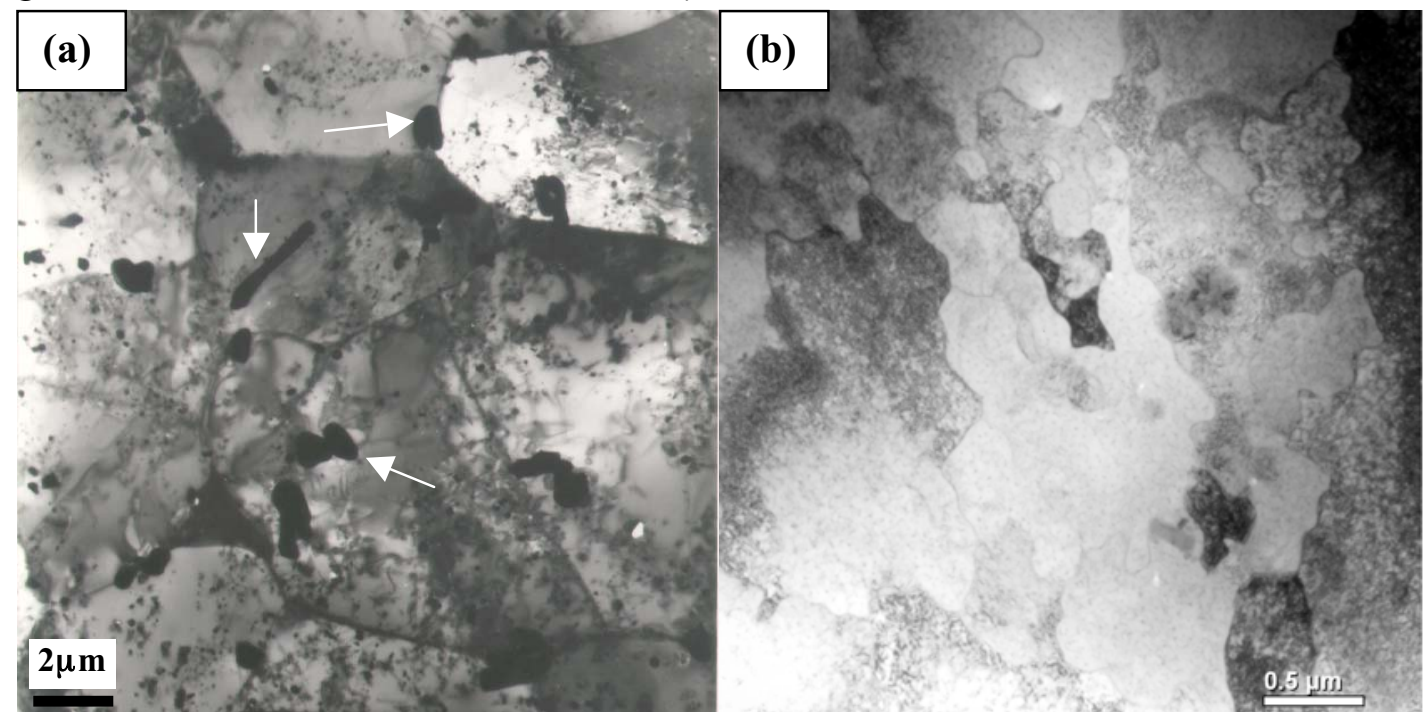

Fig. 1. TEM observations in the surface layer of the untreated (a) and 20 pulse treated (b) samples.
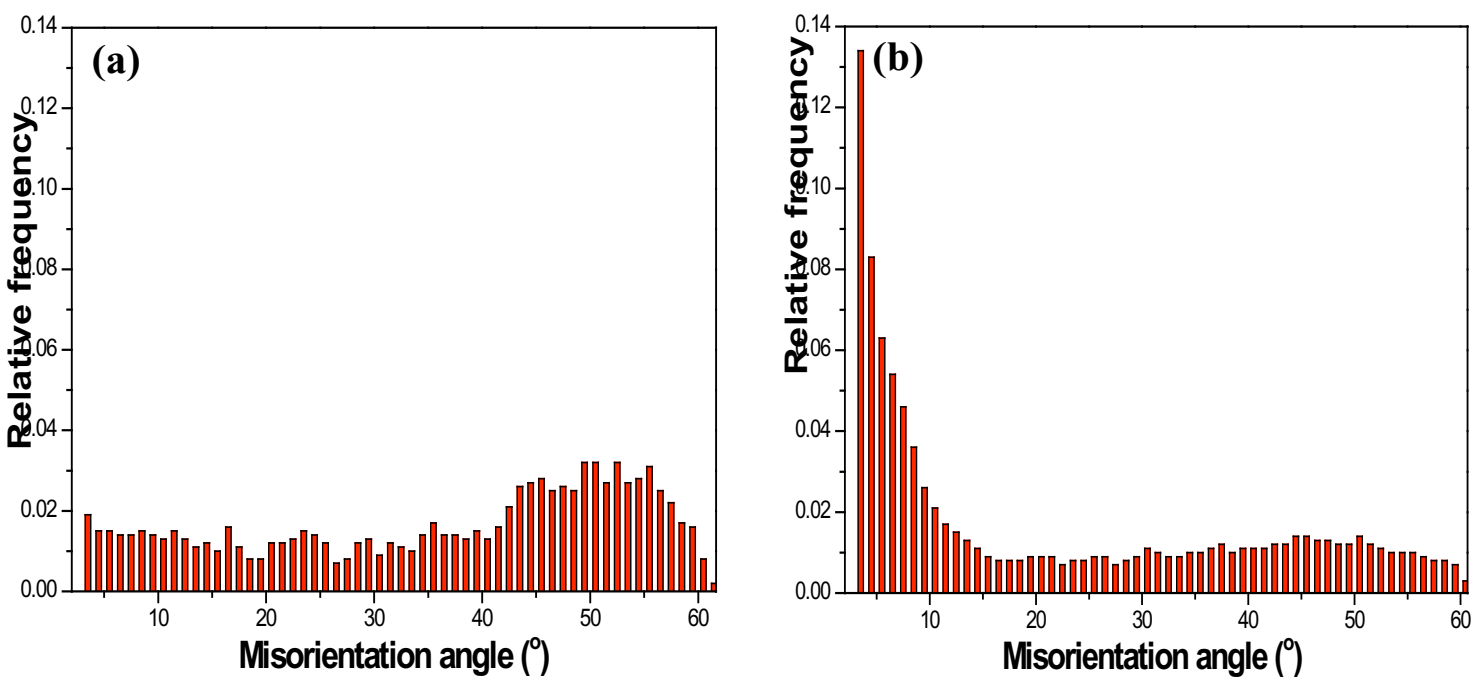

Fig. 2. Grain boundary misorientation distributions of the untreated (a) and 20 pulsed (b) samples measured by EBSD.

The typical TEM micrograph taken at the top surface of the 20 pulsed sample is shown in Fig. 1b. Compared with the microstructures in the initial sample, some different features are present. First, the oxide particles have almost completely disappeared. This indicates that a selective surface purification or homogenisation occurred. This reaction, which was observed previously under the melting mode, was triggered here without melting of the FeAl matrix ${ }^{6}$. This can be done through preferential selective melting of the impurities that were sputtered away from surface under the following pulses. Second, numerous dislocations are present in the grains, indicating a heavy deformation of the surface layer induced by the LEHCPEB treatment. Finally, dynamic recovery of the dislocation cell walls also occurred, leading to a grain refinement that was confirmed by EBSD measurements. Fig. 2 compares the grain boundary misorientation distributions of the untreated sample and that of the 20 pulsed sample. The increased fraction of low angle grain boundaries after the LEHCPEB treatment corresponds to the creation of new sub-grains inside the initial grains. As a result, the average 
grain size was refined. The determination of the so-called "grain size" by EBSD is dependent on the selection of misorientation angles. If we use a boundary misorientation angle of 5 degree for the determination of grain size, then the average grain size is about $3.6 \mu \mathrm{m}$ for the untreated sample decreasing down to $2.8 \mu \mathrm{m}$ for the 5 pulsed sample and $1.8 \mu \mathrm{m}$ for the 20 pulsed sample.

The evolution of the surface hardness $(H, \mathrm{Hv})$ as a function of the square root of the average grain size is plotted in Fig. 3. The hardness of the untreated sample is about $305 \mathrm{Hv}$. After 20 pulses, the hardness is increased to about $375 \mathrm{Hv}$, more than $25 \%$ due to the

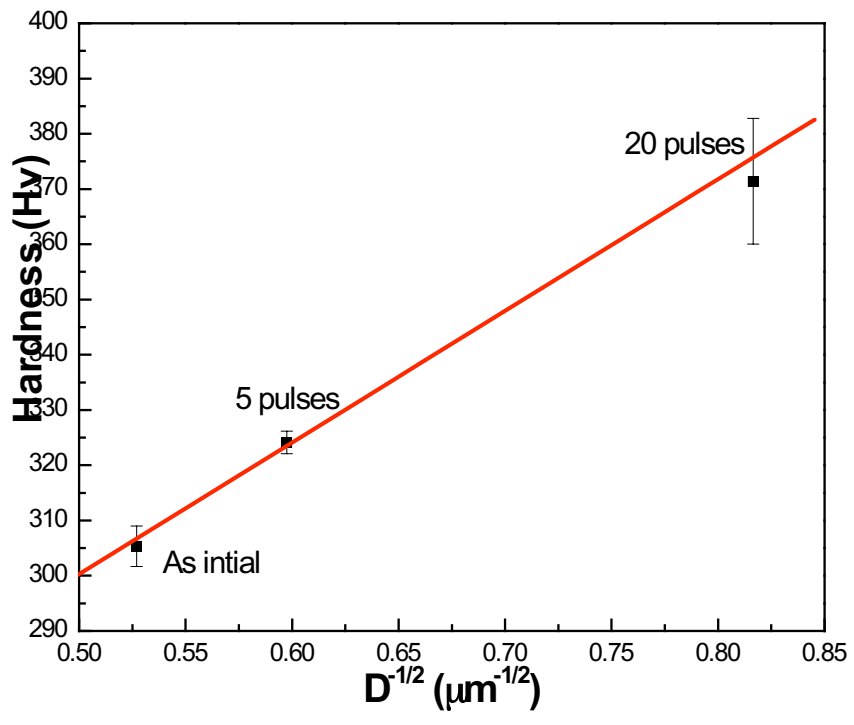

Fig. 3. Hall-Petch plot showing the evolution of the surface hardness. The Vicker's hardness was measured under a $100 \mathrm{~g}$ load.
LEHCPEB treatment. There is a fairly linear increase of hardness with the square root of the average grain size when the number of pulses increases. Despite this linear increase, it is believed that the decrease in grain size is not the only factor controlling hardness under the "heating mode". Indeed, it is very likely that the fast thermal cycles generated at the sample surface have induced the presence of vacancies which are known to affect the strength of $\mathrm{FeAl}{ }^{12-14}$. The increased dislocation density within the grains should also contribute to the increased hardness by strain hardening effect. Comparatively, however, the removal of oxide

particles should compensate these effects by the absence of precipitation hardening.

The corrosion resistance of the samples before and after the LEHCPEB treatment has also been evaluated. Typical potentiodynamic polarization curves of the untreated and treated samples in the $0.5 \mathrm{M} \mathrm{H}_{2} \mathrm{SO}_{4}$ solution are given in Fig. 4. The general trends of the curves are rather similar to the one reported in $\mathrm{H}_{2} \mathrm{SO}_{4}$ for this $\mathrm{B} 2$ alloy produced by different processing routes. ${ }^{15-17}$ The difference here between the three conditions is rather subtle. For the initial sample, the open circuit potential $E_{\text {corr }}=-560 \quad \mathrm{mV}$. It slightly decreases to $-600 \mathrm{mV}$ after the LEHCPEB treatment with 5 pulsed and down to $-620 \mathrm{mV}$ for the 20 pulsed samples. The corrosion current density $\left(i_{\text {corr }}\right)$ increased slightly from $0.2 \mathrm{~mA} / \mathrm{cm}^{2}$ for the initial sample to $1 \mathrm{~mA} / \mathrm{cm}^{2}$ for the 5 pulsed sample and then decreased to $0.8 \mathrm{~mA} / \mathrm{cm}^{2}$ for the 20 pulsed sample. For all the samples, the polarization curves show typical active-passive-transpassive behaviour compared with the

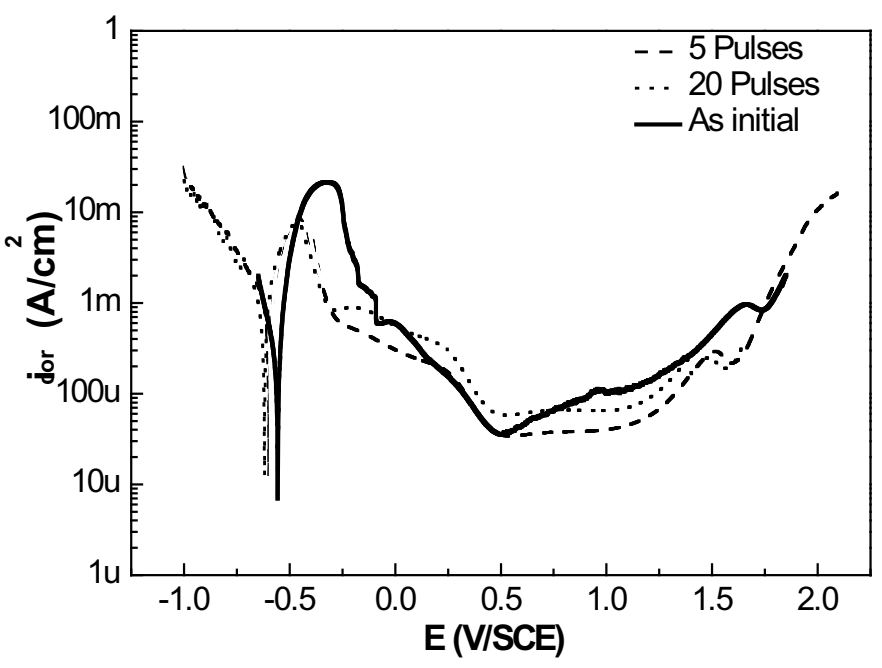

Fig. 4. Potentiodynamic polarization curves of untreated and treated samples in $0.5 \mathrm{M} \mathrm{H}_{2} \mathrm{SO}_{4}$ solution. 
samples are easier to shift toward the passive state by showing a lower potential and a lower current density at the active-passive peak. On the other hand, the treated samples also show a more stable passive region $(0.5 \mathrm{~V}-1.2 \mathrm{~V})$ with lower current density than that of the untreated sample. However, the above differences in corrosion behaviours between untreated and treated samples are rather low. In short, the polarization curves reveal that the corrosion resistance of the alloy remains at very similar level after the LEHCPEB treatment while other properties are improved.

In summary, this work has demonstrated that significant microstructure and property modifications can be encountered in a material treated with low energy, high current pulsed electron beam (LEHCPEB) under the so called "heating" mode. The oxide paticles in the initially FeAl sample can be removed without crater formations and melting of the substrate. Together with the surface purification effect, a grain refinement effect was observed. This is due to the formation of low angle grain boudaries and grain boundary migration induced by repeated deformation and dynamic recovery/recrystallization during the LEHCPEB treatment. Furthermore, surface hardening is also observed after treatment, which is likely due to the combination of grain refinement and formation of quenched-in vacancies. Comparatively, the corrosion resistance remains at the same level after the LEHCPEB treatment without melting - a good balance between hardness and corrosion resistance is thus achieved.

Acknowledgement: Dr. Zou Jianxin would like to thank the French Embassy for the provision of a "Bourse de co-tutelle" between the University of Dalian and the University Paul Verlaine - Metz. Professor Thierry Grosdidier would also like to acknowledge the support of the "Service des Relations Internationalles" from the University Paul Verlaine Metz.

1. D. I. Proskurovsky, V. P. Rotshtein, G. E. Ozur, A. B. Markov, D. S. Nazarov, J. of Vac. Sci. Tech. A. 1694, 2480 (1998).

2. Yu. Ivanov, W. Matz, V. P. Rotshtein, R. Gunzel, N. Shevchenko, Surf. Coat. Tech. 150, 188 (2003).

3. D. I. Proskurovsky, V. P. Rotshtein, G. E. Ozur, Yu. F. Ivanov, A. B. Markov, Surf. Coat. Tech. 125, 49 (2000).

4. S. Z. Hao, B. Gao, A. M. Wu, J. X. Zou, Y. Qin, C. Dong, J. An, Q. F. Guan, Nucl. Instr. Meth. in Phys. Res. $B, 240,646$ (2005).

5. J. X. Zou, T. Grosdidier, K. M. Zhang, C. Dong, Acta Mater. 54, 5409 (2006).

6. J. X. Zou, K. M. Zhang, C. Dong, Y. Qin, S. Z. Hao, T. Grosdidier, Appl Phys Lett. 89, 041913 (2006).

7. J. X. Zou, K. M. Zhang, T. Grosdidier, C. Dong, S. Z. Hao, D. Z. Yang, Materials Science and Engineering A, 2007, In press.

8. T. Grosdidier, J. X. Zou, N. Stein, C. Boulanger, S. Z. Hao, C. Dong, Scripta Mater. 2008, In press.

9. T. Grosdidier, E. Suzon, F. Wagner, Intermetallics, 12, 645 (2004).

10. J. Gang, J. P. Morniroli, T. Grosdidier, Scripta Mater. 48, 1599 (2003).

11. T. Grosdider, G. Ji, N. Bozollo, Intermetallics, 14, 715 (2006).

12. J. Rieu, C. Goux, Rev. Metall. 66, 869 (1969).

13. A. Kellou, H. Feraoun, T. Grosdidier, C. Coddet, H. Aourag. Acta Mater. 52, 3263 (2004).

14. A. Kellou, T. Grosdidier, H. Aourag, Intermetallics, 14, 142 (2006).

15. S. Frangini, Corrosion Science, 39, 1943 (1997).

16. O. Elkedim, S. Paris, G. Phigini, F. Bernard, E. Gaffet, Z. A. Munir, Mater. Sci. Eng. A, 369, 49 (2004).

17. G. Ji, O. Elkedim, T. Grosdidier, Surf. Coat. Tech. 190, 406 (2005). 